\title{
Effect of the angiotensin receptor blocker irbesartan on metabolic parameters in clinical practice: the DO-IT prospective observational study
} Klaus G Parhofer*1, Felix Münzel² and Michael Krekler²

\author{
Address: ${ }^{1}$ Medical Department II - Grosshadern, University Munich, Marchioninistr. 15, 81377 Munich, Germany and ${ }^{2}$ Bristol-Myers Squibb \\ GmbH, Sapporobogen 6-8, 80637 Munich, Germany \\ Email: Klaus G Parhofer* - klaus.parhofer@med.uni-muenchen.de; Felix Münzel -felix.muenzel@gmx.de; \\ Michael Krekler - michael.krekler@bms.com \\ * Corresponding author
}

Published: 27 November 2007

Cardiovascular Diabetology 2007, 6:36 doi:10.1186/1475-2840-6-36

This article is available from: http://www.cardiab.com/content/6/1/36

(C) 2007 Parhofer et al; licensee BioMed Central Ltd.

This is an Open Access article distributed under the terms of the Creative Commons Attribution License (http://creativecommons.org/licenses/by/2.0), which permits unrestricted use, distribution, and reproduction in any medium, provided the original work is properly cited.
Received: 26 September 2007

Accepted: 27 November 2007

\begin{abstract}
Aims: A number of intervention studies have shown that therapy with angiotensin receptor blockers, such as irbesartan, can improve metabolic parameters and reduce the incidence of diabetes mellitus. It is unknown whether this observation also holds true in routine clinical settings.

Methods: We evaluated the effect of irbesartan (I50 mg or $300 \mathrm{mg} / \mathrm{d}$ ) together with or without hydrochlorothiazide ( $12.5 \mathrm{mg} / \mathrm{d}$ ) in 3259 German patients. A total of 750 primary care physicians evaluated up to 5 subsequent patients with metabolic syndrome (58.9\% diabetic), in whom irbesartan therapy was newly initiated (87\%) or continued (13\%).

Results: Six months of irbesartan therapy decreased systolic blood pressure by $14 \%$ (I57.4 \pm I4.7 vs. I $35.0 \pm 10.7 \mathrm{mmHg}$ ) and diastolic blood pressure by I $3 \%(92.9 \pm 9.2 \mathrm{vs.} 80.8 \pm 6.8 \mathrm{mmHg})$. This was associated with a decrease in body weight (-2.3\%), fasting glucose $(-9.5 \%), \mathrm{HbAlc}(-4.6 \%)$, LDLcholesterol (-I I\%), triglycerides (-16\%) and gamma-GT (-I2\%) and an increase in HDL-cholesterol $(+5 \%)$. These changes were somewhat more pronounced in male than in female patients and in obese than in lean patients. Changes in glucose concentration and $\mathrm{HbAlc}$ were much more prominent in diabetic patients.
\end{abstract}

Conclusion: Irbesartan therapy improves metabolic parameters in routine clinical settings. Thus, our study confirms previously published results from large intervention trials and extends the findings to routine clinical practice.

\section{Introduction}

The metabolic syndrome which describes the concomitant presence of visceral obesity, insulin resistance or glucose intolerance, atherogenic dyslipidemia and hypertension is highly prevalent (approximately 25\%) in Germany. The risk of developing diabetes mellitus type 2 for subjects with the metabolic syndrome is increased five- to nine-fold [1,2]. In addition, all components of the metabolic syndrome are common cardiovascular risk factors. Therefore patients with this syndrome have a two-four fold increase in risk for cardiovascular disease and death [3]. 
Large clinical trials evaluated the effect of angiotensin receptor blockers (ARB) on cardiovascular end points, generally showing very positive results. Therefore ARB and ACE-Inhibitors are now considered first line therapy in hypertensive patients with the metabolic syndrome $[4,5]$. An analysis of co-morbidity showed that such therapy also substantially lowers the risk for type 2 diabetes compared with other antihypertensive drugs and compared with placebo [6-8]. Furthermore, it lowers cardiovascular mortality independent of its antihypertensive effects. The reduced incidence of diabetes in ARB trials was associated with lowering of blood pressure, but independent of other predictors for diabetes development. Furthermore, an anti-inflammatory effect by treatment was observed, as well as an influence on the metabolism of free fatty acids, which could mediate the observed reduction in type 2 diabetes incidence. On the other hand, a recently published intervention trial which specifically aimed at reducing the incidence of type 2 diabetes with the ACE inhibitor ramipril failed to show a significant reduction in new onset diabetes, although average glucose concentration was decreased compared to placebo [9].

Thus, a large body of data indicates that interfering with the angiotensin system has positive effects on metabolic parameters. However, it is unknown whether these positive effects can also be observed in daily routine clinical practice, although recently published data from a post authorization trial indicate that this may be the case [10]. We therefore conducted an observational study in a large group of German hypertensive patients. The aim of this study was to evaluate the effect of irbesartan with and without hydrochlorothiazide on parameters of glucose metabolism, lipid metabolism, renal function, and blood pressure.

\section{Methods}

A total of 3259 patients participated in this prospective, 6month, open-label, observational, post-authorization survey. The patients were recruited from 649 general practitioners throughout Germany, who included up to 5 subsequent patients who fulfilled the inclusion criteria specified below and who at the time of the index visit were either already on irbesartan therapy or in whom irbesartan therapy was started at that time point. All subjects had elevated blood pressure (>130/85 mmHg or antihypertensive therapy). In addition, at least two of the following criteria were present: abdominal obesity (waistcircumference $>102 \mathrm{~cm}$ (male) or $>88 \mathrm{~cm}$ (female)), elevated triglycerides $(>150 \mathrm{mg} / \mathrm{dl})$, decreased HDL-cholesterol (male $<40 \mathrm{mg} / \mathrm{dl}$, female $<50 \mathrm{mg} / \mathrm{dl}$ ), elevated fasting glucose $(>110 \mathrm{mg} / \mathrm{dl})$. The characteristics of the subjects are shown in Table 1.

Each subject was evaluated three times: At baseline (index visit), after three months and after six months. Patients were evaluated using a standardized form with which data on duration of hypertension, duration of metabolic syndrome, nicotine and alcohol consumption, blood pressure, pulse, weight, height, waist circumference, medications, lab-values (HbA1c, fasting glucose, fasting LDL-cholesterol, fasting HDL-cholesterol, fasting triglycerides, creatinine, hs-CRP, gamma-GT) were collected.

Mean and standard deviation as well as median and range were used to describe the population. t-tests were used to evaluate intergender differences, differences between diabetic and non-diabetic patients, and differences between different doses. Non-parametric tests were used for statistical evaluation were appropriate. SAS, version 9.1 was used for statistical analysis. The analysis was performed by GKM - Gesellschaft fuer Therapieforschung, Munich, Germany.

Table I: Parameters of study participants at baseline

\begin{tabular}{lccc}
\hline Parameter & All & Men & Women \\
\hline $\mathrm{n}$ & 3259 & $64.1 \%$ & $35.9 \%$ \\
Age [years] & $61.5 \pm 10.5$ & $60.2 \pm 10.0$ & $63.7 \pm 10.8^{*}$ \\
BMI [kg/m²] & $30.9 \pm 4.8$ & $30.8 \pm 4.4$ & $31.0 \pm 5.3$ \\
Waist-circumference [cm] & $106.4 \pm 13.6$ & $110.2 \pm 11.9$ & $99.2 \pm 13.7^{*}$ \\
$\mathrm{RR}_{\text {systolic }}[\mathrm{mmHg}]$ & $157.4 \pm 14.7$ & $157.5 \pm 14.5$ & $157.2 \pm 15.1$ \\
RR & $92.9 \pm 9$ & $93.3 \pm 9.1$ & $92.2 \pm 9.5^{*}$ \\
Fasting plasma glucose (FPG) [mg/ & $126.4 \pm 37.1$ & $126.6 \pm 37.3$ & $126.0 \pm 36.7$ \\
dl] & & $144.8 \pm 38.5$ & $145.2 \pm 37.5$ \\
LDL-cholesterol [mg/dl] & $144.9 \pm 38.2$ & $46.2 \pm 30.9$ & $52.6 \pm 33.2^{*}$ \\
HDL-cholesterol [mg/dl] & $48.4 \pm 31.8$ & $209.9 \pm 85.8^{*}$ \\
Triglycerides [mg/dl] & $217.4 \pm 114.9$ & $3.75 \pm 6.26$ \\
Hs-CRP [mg/l] & $4.81 \pm 7.95$ & $5.13 \pm 8.38$ & $40.6 \pm 34.8^{*}$ \\
Gamma-GT [U/l] & $52.9 \pm 47.1$ & $58.7 \pm 50.6$ & \\
\hline
\end{tabular}

$\mathrm{BMI}=$ body-mass index; ${ }^{*} \mathrm{p}<0.01$ for intergender differences; 


\section{Results}

In this cohort of German hypertensive patients $49.1 \%$ did not take any antihypertensive medications at the index visit, while $50.9 \%$ were taking at least one antihypertensive drug. At baseline 423 patients (13.2\%) were taking irbesartan, while in all others irbesartan therapy was initiated at the index visit. Furthermore, the patients were also taking a significant number of other medications (Table 2). This concomitant medication did not change during the observation period.

In this study 594 patients $(18.8 \%)$ were treated with irbesartan $150 \mathrm{mg} / \mathrm{d}, 665$ patients (21\%) with irbesartan 300 $\mathrm{mg} / \mathrm{d}, 754$ patients (23.8\%) with $150 \mathrm{mg}$ irbesartan and $12.5 \mathrm{mg}$ hydrochlorothiazide and the rest (36.4\%) with irbesartan $300 \mathrm{mg} / \mathrm{d}$ and $12.5 \mathrm{mg}$ hydrochlorothiazide. During the observation period the number of patients treated with irbesartan $150 \mathrm{mg} / \mathrm{d}$ decreased slightly (from $42.6 \%$ to $37.0 \%$ ) while those groups taking $300 \mathrm{mg} / \mathrm{d}$ increased (from $57.4 \%$ to $63 \%$ ).

Within the observation period ( 6 months) systolic blood pressure decreased from $157.4 \pm 14.7 \mathrm{mmHg}$ to $135.0 \pm$ $10.9 \mathrm{mmHg}(-22.3 \%)$. Diastolic blood pressure decreased from $92.9 \pm 9.2 \mathrm{mmHg}$ to $80.8 \pm 6.8 \mathrm{mmHg}(-12.1 \%)$. Thus, the rate of patients with systolic blood pressure $<130 \mathrm{mmHg}$ increased from $1.6 \%$ to $20.4 \%$. While the rate of patients with systolic blood pressure $>180 \mathrm{mmHg}$ decreased from 9.4 to $0.4 \%$. Similarly, diastolic blood pressure was $<85 \mathrm{mmHg}$ in $15.7 \%$ at the index visit and $67 \%$ after 6 months of therapy. The rate of patients who

Table 2: Accompanying diagnosis and medication at baseline

\begin{tabular}{lcc}
\hline Parameter & $\mathbf{n}$ & $\% *$ \\
\hline Diabetes mellitus & 1921 & 58.9 \\
Hepatic steatosis & 1258 & 38.6 \\
Coronary artery disease & 773 & 23.7 \\
Benign prostatic hyperplasia & 365 & 11.2 \\
Nephropathy & 315 & 9.7 \\
Cardiac failure & 306 & 9.4 \\
Myocardial infarction & 272 & 8.3 \\
Cerebrovascular event & 176 & 5.4 \\
Active smoker & 680 & 20.9 \\
Former smoker & 1012 & 31.1 \\
Statins & 1471 & 45.1 \\
Orale antidiabetic drugs & 1298 & 39.8 \\
Betablockers & 1088 & 33.4 \\
Platelet Inhibitors & 957 & 29.4 \\
Calciumantagonists & 735 & 22.6 \\
Diuretics & 637 & 19.5 \\
Insulin & 420 & 12.9 \\
ACE-Inhibitors & 337 & 10.3 \\
Fibrates & 200 & 6.1 \\
\hline
\end{tabular}

Medications reported in less than $3 \%$ are not indicated in the table; $*$ sum $>100 \%$ because some patients were taking more than I medication. had blood pressure $<140 / 90 \mathrm{mmHg}$ increased from 4.9 to $59.2 \%$.

During the observation period the body weight decreased from $91.4 \pm 15 \mathrm{~kg}$ to $89.3 \pm 14.6 \mathrm{~kg}(-2.2 \%)$. This decrease was somewhat more pronounced in men $(-2.5 \%)$ than in women $(-1.4 \%)$. Similarly waist circumference decreased from 106.4 to $104.3 \mathrm{~cm}$ (all: $-2.1 \%$; men -2.6\%; women $1.3 \%)$.

The effect on metabolic parameters is shown in Table 3. Overall we observed a reduction in HbA1c, fasting glucose, LDL-cholesterol, fasting triglycerides, Hs-CRP, Gamma-GT and an increase in HDL-cholesterol. Generally, these changes in metabolic parameters were more pronounced in patients receiving $300 \mathrm{mg}$ irbesartan/d compared to those receiving $150 \mathrm{mg} / \mathrm{d}$ (Table 4). The effect on metabolic parameters was independent of the medication that the patients were receiving at the index visit.

All metabolic changes were more pronounced in men than in women, in younger ( $<62$ years) than in older $(\geq 62$ years), in more obese (BMI $\geq 30 \mathrm{~kg} / \mathrm{m}^{2}$ ) than in leaner patients. HbA1c and fasting glucose reduction was significant in diabetic and non-diabetic patients, but was much more pronounced in those with diabetes. All other parameters decreased in diabetic and non-diabetic patients, however, improvement was overall more pronounced in patients with diabetes (Figure 1). Within the group of diabetic patients we did not observe an influence of the underlying anti-diabetic treatment on the metabolic efficacy of irbesartan (data not shown). In a multivariate analysis it was shown that changes in HbA1c and glucose were mostly related to BMI while changes in LDL-cholesterol and triglycerides were related to age. Furthermore, triglycerides, HDL-cholesterol and HbA1c were correlated with sex.

All metabolic changes were significantly correlated with the changes in blood pressure, although the correlation coefficients were low (Table 5). Changes in systolic blood pressure correlated best with changes in HbA1c, while changes in diastolic blood pressure correlated best with changes in LDL-cholesterol and triglycerides.

\section{Discussion}

In our study performed in routine clinical practice six months of irbesartan therapy resulted in a considerable improvement in a number of metabolic parameters. We observed a significant reduction in $\mathrm{HbA} 1 \mathrm{c}$, fasting glucose, LDL-cholesterol, fasting triglycerides, gamma-GT and hs-CRP. 
Table 3: Effect of irbesartan on metabolic parameters in patients with metabolic syndrome

\begin{tabular}{|c|c|c|c|c|c|}
\hline Parameter & Baseline & On Therapy & Change $^{a}$ & Change $^{b}$ & p-value \\
\hline Body weight $[\mathrm{kg}]$ & $91.4 \pm 15.0$ & $89.3 \pm 14.6$ & $-2.1 \pm 7.9$ & -2.3 & $<0.0001$ \\
\hline Waist-circumference $[\mathrm{cm}]$ & $106.4 \pm 13.6$ & $104.3 \pm 13.2$ & $-2.1 \pm 7.9$ & -2.0 & $<0.0001$ \\
\hline $\mathrm{RR}_{\text {systolic }}[\mathrm{mmHg}]$ & $157.4 \pm 14.7$ & $135.0 \pm 10.7$ & $-22.3 \pm 15.3$ & -14.2 & $<0.0001$ \\
\hline $\mathrm{RR}_{\text {diastolic }}[\mathrm{mmHg}]$ & $92.9 \pm 9.2$ & $80.8 \pm 6.8$ & $-12.1 \pm 9.9$ & -13.0 & $<0.0001$ \\
\hline Glucose $[\mathrm{mg} / \mathrm{dl}]$ & $126.4 \pm 37.1$ & $114.5 \pm 29.4$ & $-12.0 \pm 30.7$ & -9.5 & $<0.0001$ \\
\hline $\mathrm{HbAlc}[\%]$ & $6.74 \pm 1.14$ & $6.43 \pm 0.91$ & $-0.31 \pm 0.75$ & -4.6 & $<0.0001$ \\
\hline LDL-cholesterol [mg/dl] & $144.9 \pm 38.2$ & $\mid 29.1 \pm 31.8$ & $-15.8 \pm 30.5$ & -10.9 & $<0.0001$ \\
\hline HDL-cholesterol [mg/dl] & $48.4 \pm 31.8$ & $51.0 \pm 15.9$ & $2.6 \pm 31.8$ & 5.4 & $<0.0001$ \\
\hline Triglycerides [mg/dl] & $217.4 \pm 114.9$ & $182.5 \pm 76.7$ & $-34.9 \pm 100.9$ & -16.1 & $<0.0001$ \\
\hline Gamma-GT [U/l] & $52.9 \pm 47.1$ & $46.8 \pm 38.9$ & $-6.1 \pm 30.2$ & -11.5 & $<0.0001$ \\
\hline $\mathrm{Hs}-\mathrm{CRP}[\mathrm{mg} / \mathrm{l}]$ & $4.81 \pm 7.95$ & $4.01 \pm 6.74$ & $-0.79 \pm 6.72$ & -16.4 & $<0.0001$ \\
\hline
\end{tabular}

a absolute change; b relative change (\%); ${ }^{\mathrm{p}} \mathrm{p}$-values for absolute change

These changes in metabolic parameters were somewhat dose dependent, thus more pronounced in patients receiving $300 \mathrm{mg}$ irbesartan compared to those receiving $150 \mathrm{mg} / \mathrm{d}$. Concomitant therapy with thiazide did not affect these changes. Overall the metabolic changes were more pronounced in men and more pronounced in overweight and obese subjects. The observed changes were strongly related to changes in blood pressure.

Our observations are consistent with previous intervention trials. Large clinical trials showed that ARB therapy substantially lowers the risk for type 2 diabetes compared to other antihypertensive therapies or placebo [6-8]. Furthermore, in a recently published subanalysis of the Treat to Target post authorization survey in 14200 patients very similar results were observed. There was a significant improvement in blood pressure and metabolic risk factors as a result of Irbesartan treatment. Similar to our study there was no evidence of a difference between monotherapy and combination therapy with hydrochlorothiazide with regard to the cardiovascular risk profile [10]. While Kintscher and colleagues [10] investigated hypertensive patients with and without metabolic syndrome, we studies only metabolic syndrome patients including a large number of diabetic patients. Despite this difference the over-all results are very similar indicating that a broad range of patients benefit from such therapy with respect to metabolic parameters. However, it should also be noted that in both studies patients with supposedly more severe insulin resistance benefited the most.

In addition, a number of small clinical trials have evaluated the effect of $\mathrm{ARB}$ therapy on individual components of the metabolic syndrome particularly on glucose metabolism [11-13]. It is currently unclear whether individual ARB differ in their potential to improve metabolic parameters, although telmisartan and irbesartan seem to be particularly powerful in this respect $[14,15]$.

Several mechanisms could link ARB therapy with an improvement in metabolic parameters. ARB may improve insulin sensitivity by affecting inflammatory processes and altering free fatty acid concentration and/or metabolism [16]. Furthermore, ARB could directly stimulate PPAR-gamma [17-19].

Our study extends the known findings to the "every day" routine clinical practice. The magnitude of improvement

Table 4: Dose dependent effects of irbesartan on metabolic parameters in patients with metabolic syndrome

\begin{tabular}{|c|c|c|c|c|c|c|}
\hline Parameter & 150 mg/da & $300 \mathrm{mg} / \mathrm{d}^{\mathrm{a}}$ & p-value ${ }^{b}$ & 150 mg/d + HCTa & $300 \mathrm{mg} / \mathrm{d}+$ HCT $^{\mathrm{a}}$ & p-value ${ }^{c}$ \\
\hline Glucose $[\mathrm{mg} / \mathrm{dl}]$ & $-9.1 \pm 30.5$ & $-12.3 \pm 34.7$ & 0.092 & $-7.8 \pm 23.9$ & $-14.3 \pm 30.7$ & $<0.0001$ \\
\hline $\mathrm{HbAlc}[\%]$ & $-0.24 \pm 0.8$ & $-0.30 \pm 0.8$ & 0.223 & $-0.26 \pm 0.6$ & $-0.34 \pm 0.7$ & 0.035 \\
\hline LDL-cholesterol [mg/dl] & $-11.2 \pm 26.92$ & $-16.6 \pm 30.4$ & 0.004 & $-12.4 \pm 26.4$ & $-17.3 \pm 33.3$ & 0.001 \\
\hline HDL-cholesterol [mg/dl] & $1 \pm 37.4$ & $2.8 \pm 25.6$ & 0.393 & $2.1 \pm 22.6$ & $4.1 \pm 33.6$ & 0.156 \\
\hline Triglycerides [mg/dl] & $-27.4 \pm 75.8$ & $-31.0 \pm 73.6$ & 0.440 & $-30.9 \pm 68.9$ & $-40.3 \pm 133.9$ & 0.060 \\
\hline Gamma-GT [U/l] & $-4.7 \pm 37.2$ & $-7.3 \pm 24.2$ & 0.257 & $-4.2 \pm 21.7$ & $-6.4 \pm 32.4$ & 0.142 \\
\hline $\mathrm{Hs}-\mathrm{CRP}[\mathrm{mg} / \mathrm{l}]$ & $-0.42 \pm 2.9$ & $-0.80 \pm 10.5$ & 0.704 & $-0.47 \pm 1.4$ & $-1.25 \pm 7.2$ & 0.111 \\
\hline
\end{tabular}

a absolute change; ${ }^{b}$ relates to difference between irbesartan $150 \mathrm{mg} / \mathrm{d}$ and irbesartan $300 \mathrm{mg} / \mathrm{d}$; c relates to difference between irbesartan $150 \mathrm{mg} / \mathrm{d}$ with HCT (12.5 mg/d) and irbesartan $300 \mathrm{mg} / \mathrm{d}$ with HCT (12.5 mg/d). 


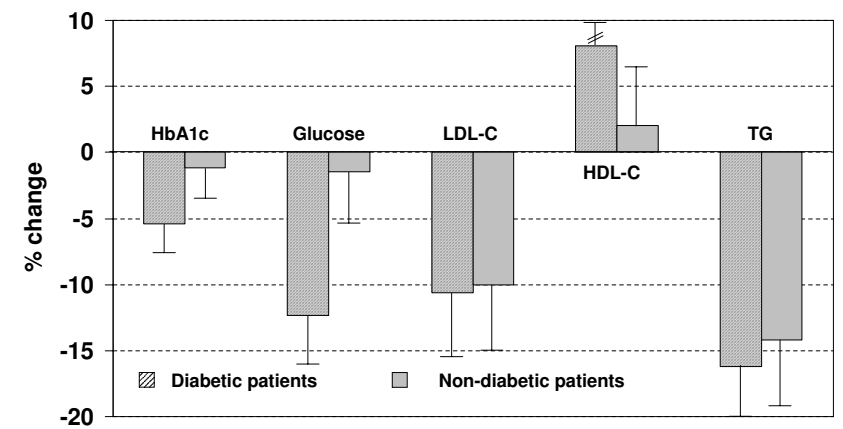

\section{Figure I}

Effect of irbesartan on metabolic parameters in diabetic and non-diabetic patients with metabolic syndrome. All changes from baseline are significant $(p<0.001)$. Differences between diabetic and non-diabetic subjects are only significant for HbAlc $(p<0.000 \mathrm{l})$, fasting glucose $(p<0.000 \mathrm{I})$, and HDLcholesterol $(p=0.05)$, while differences between diabetic and non-diabetic patients were not significant concerning triglycerides $(p=0.148)$ and LDL-cholesterol $(p=0.819)$.

is similar to that seen in placebo controlled intervention trials. It is however important to confirm these studies in more typical settings, because patients included in placebo controlled intervention trials are usually highly selected which could bias results. On the other hand our open-label, observational design also results in considerable limitations. Thus, it should be noted, that all subgroups including those that were already on ARB therapy or ACE inhibitor therapy at the beginning benefited with respect to their metabolic parameters. This indicates that part of the improvement in metabolic parameters is related to the fact that the patients were included in this observational study (study-in effect). Notably, we also observed a small but significant decrease in body weight, which also indicates that some of the beneficial effects observed during the study are related to the study-in effect. On the other hand, as outlined above, irbesartan stimulates PPAR-gamma dependent pathways and thus results in an altered flux of free fatty acids, which may affect nutritional behavior and caloric intake. Furthermore, metabolic improvement was related to blood pressure reduction. It therefore cannot be decided whether the improvement in metabolic parameters is specific for irbe- sartan (or ARB therapy) or the result of blood pressure reduction. However, a number of large intervention trials have shown that the effect of ARB therapy on metabolic parameters reaches beyond blood pressure reduction.

\section{Conclusion}

The present study indicates that hypertensive patients with metabolic syndrome with and without diabetes benefit from irbesartan therapy not only with respect to blood pressure reduction but also with respect to a significant improvement of metabolic parameters such as glucose, lipids and liver values.

\section{Competing interests}

KGP has received speaker's fees from Bristol-Myers Squibb.

\section{Authors' contributions}

KG participated in the design of the study and the analysis of the data and drafted the manuscript. FM participated in the design of the study and helped to draft the manuscript. MK conceived of the study, and participated in its design and coordination and helped to draft the manuscript. All authors read and approved the final manuscript.

\section{Acknowledgements}

The study was supported by a grant from Bristol-Myers Squibb $\mathrm{GmbH}$, Munich, Germany.

\section{References}

I. Balkau B, Vernay M, Mhamdi L, Novak M, Arondel D, Vol S, Tichet J Eschwege $E:$ The incidence and persistence of the NCEP (National Cholesterol Education Program) metabolic syndrome. The French D.E.S.I.R. study. Diabetes Metab 2003, 29:526-532.

2. Sattar N, Gaw A, Scherbakova O, Ford I, O'Reilly DS, Haffner SM, Isles C, Macfarlane PW, Packard C], Cobbe SM, Shepherd J: Metabolic syndrome with and without C-reactive protein as a predictor of coronary heart disease and diabetes in the West of Scotland Coronary Prevention Study. Circulation 2003, 108:414-4I9.

3. Isomaa B, Almgren P, Tuomi T, Forsen B, Lahti K, Nissen M, Taskinen MR, Groop L: Cardiovascular morbidity and mortality associated with the metabolic syndrome. Diabetes Care 200I, 24:683-689.

4. Israili ZH, Lyoussi B, Hernandez-Hernandez R, Velasco M: Metabolic syndrome: treatment of hypertensive patients. Am J Ther 2007, 1 4:386-402.

Table 5: Correlations between changes in blood pressure and changes in metabolic parameters

\begin{tabular}{lcccc}
\hline Parameter & \multicolumn{2}{c}{ Systolic blood pressure } & \multicolumn{2}{c}{ Diastolic blood pressure } \\
& r & $\mathbf{p}$ & $\mathbf{r}$ \\
\hline HbAlc [\%] & 0.114 & $<0.0001$ & 0.064 & 0.002 \\
Glucose [mg/dl] & 0.078 & $<0.0001$ & 0.045 & 0.016 \\
LDL-cholesterol [mg/dL] & 0.097 & $<0.0001$ & 0.132 & $<0.0001$ \\
HDL-cholesterol [mg/dL] & -0.025 & ns & -0.064 & 0.001 \\
Triglycerides [mg/dl] & 0.085 & $<0.0001$ & 0.115 & $<0.0001$
\end{tabular}


5. Sowers JR, Neutel JM, Saunders E, Bakris GL, Cushman WC, Ferdinand KC, Ofili EO, Weber MA: Antihypertensive efficacy of Irbesartan/HCTZ in men and women with the metabolic syndrome and type 2 diabetes. J Clin Hypertens (Greenwich) 2006, 8:470-480.

6. Julius S, Kjeldsen SE, Weber M, Brunner HR, Ekman S, Hansson L, Hua T, Laragh J, Mclnnes GT, Mitchell L, Plat F, Schork A, Smith B, Zanchetti $A$ : Outcomes in hypertensive patients at high cardiovascular risk treated with regimens based on valsartan or amlodipine: the VALUE randomised trial. Lancet 2004, 363:2022-203I.

7. Dahlof B, Devereux RB, Kjeldsen SE, Julius S, Beevers G, de Faire U, Fyhrquist $\mathrm{F}$, Ibsen $\mathrm{H}$, Kristiansson $\mathrm{K}$, Lederballe-Pedersen $\mathrm{O}$, Lindholm LH, Nieminen MS, Omvik P, Oparil S, Wedel H: Cardiovascular morbidity and mortality in the Losartan Intervention For Endpoint reduction in hypertension study (LIFE): a randomised trial against atenolol. Lancet 2002, 359:995-1003.

8. Lindholm LH, Ibsen H, Dahlof B, Devereux RB, Beevers G, de Faire $U$, Fyhrquist F, Julius S, Kjeldsen SE, Kristiansson K, Lederballe-Pedersen O, Nieminen MS, Omvik P, Oparil S, Wedel H, Aurup P, Edelman J, Snapinn S: Cardiovascular morbidity and mortality in patients with diabetes in the Losartan Intervention For Endpoint reduction in hypertension study (LIFE): a randomised trial against atenolol. Lancet 2002, 359:1004-1010.

9. Gerstein HC, Yusuf S, Bosch J, Pogue J, Sheridan P, Dinccag N, Hanefeld M, Hoogwerf B, Laakso M, Mohan V, Shaw J, Zinman B, Holman RR: Effect of rosiglitazone on the frequency of diabetes in patients with impaired glucose tolerance or impaired fasting glucose: a randomised controlled trial. Lancet 2006, 368:1096-1105.

10. Kintscher U, Bramlage P, Paar WD, Thoenes M, Unger T: Irbesartan for the treatment of hypertension in patients with the metabolic syndrome: a sub analysis of the Treat to Target post authorization survey. Prospective observational, two armed study in 14,200 patients. Cardiovasc Diabetol 2007, 6: 12 .

II. Derosa G, Cicero AF, Bertone G, Piccinni MN, Fogari E, Ciccarelli L, Fogari R: Comparison of the effects of telmisartan and nifedipine gastrointestinal therapeutic system on blood pressure control, glucose metabolism, and the lipid profile in patients with type 2 diabetes mellitus and mild hypertension: a I2month, randomized, double-blind study. Clin Ther 2004, 26: $1228-1236$

12. Derosa G, Ragonesi PD, Mugellini A, Ciccarelli L, Fogari R: Effects of telmisartan compared with eprosartan on blood pressure control, glucose metabolism and lipid profile in hypertensive, type 2 diabetic patients: a randomized, double-blind, placebo-controlled 12-month study. Hypertens Res 2004, 27:457-464

13. Nagel JM, Tietz AB, Goke B, Parhofer KG: The effect of telmisartan on glucose and lipid metabolism in nondiabetic, insulinresistant subjects. Metabolism 2006, 55: | |49- I I54.

14. Derosa G, Fogari E, D'Angelo A, Cicero AF, Salvadeo SA, Ragonesi PD, Ferrari I, Gravina A, Fassi R, Fogari R: Metabolic effects of telmisartan and irbesartan in type 2 diabetic patients with metabolic syndrome treated with rosiglitazone. J Clin Pharm Ther 2007, 32:26I-268.

15. Negro R, Formoso G, Hassan H: The effects of irbesartan and telmisartan on metabolic parameters and blood pressure in obese, insulin resistant, hypertensive patients. I Endocrinol Invest 2006, 29:957-96I.

16. Munoz MC, Argentino DP, Dominici FP, Turyn D, Toblli JE: Irbesartan restores the in-vivo insulin signaling pathway leading to Akt activation in obese Zucker rats. J Hypertens 2006, 24:1607-1617

17. Benson SC, Pershadsingh HA, Ho Cl, Chittiboyina A, Desai P, Pravenec M, Qi N, Wang J, Avery MA, Kurtz TW: Identification of telmisartan as a unique angiotensin II receptor antagonist with selective PPARgamma-modulating activity. Hypertension 2004, 43:993-1002.

18. Clasen R, Schupp M, Foryst-Ludwig A, Sprang C, Clemenz M, Krikov $M$, Thone-Reineke C, Unger T, Kintscher U: PPARgamma-activating angiotensin type-I receptor blockers induce adiponectin. Hypertension 2005, 46: I37-I43.

19. Pershadsingh HA: Treating the metabolic syndrome using angiotensin receptor antagonists that selectively modulate peroxisome proliferator-activated receptor-gamma. Int J Biochem Cell Biol 2006, 38:766-78I.
Publish with Biomed Central and every scientist can read your work free of charge

"BioMed Central will be the most significant development for disseminating the results of biomedical research in our lifetime. "

Sir Paul Nurse, Cancer Research UK

Your research papers will be:

- available free of charge to the entire biomedical community

- peer reviewed and published immediately upon acceptance

- cited in PubMed and archived on PubMed Central

- yours - you keep the copyright 